\title{
The Open-Access Movement is Not Really about Open Access
}

\author{
Jeffrey Beall
}

Auraria Library, University of Colorado Denver, Denver, Colorado, USA, jeffrey.beall@ucdenver.edu, http://scholarlyoa.com

\begin{abstract}
While the open-access (OA) movement purports to be about making scholarly content open-access, its true motives are much different. The OA movement is an anti-corporatist movement that wants to deny the freedom of the press to companies it disagrees with. The movement is also actively imposing onerous mandates on researchers, mandates that restrict individual freedom. To boost the open-access movement, its leaders sacrifice the academic futures of young scholars and those from developing countries, pressuring them to publish in lower-quality open-access journals. The open-access movement has fostered the creation of numerous predatory publishers and standalone journals, increasing the amount of research misconduct in scholarly publications and the amount of pseudo-science that is published as if it were authentic science.
\end{abstract}

Keywords: scholarly communication, scholarly publishing, predatory publishers, open access, anti-corporatism, collectivism, pseudo-science, social movements, freedom of the press

\section{Introduction}

If you ask most open-access (OA) advocates about scholarly publishing, they will tell you that we are in a crisis situation. Greedy publishers have ruined scholarly communication, they'll claim, placing work they obtained for free behind expensive paywalls, locking up research that the world needs to progress.

The OA zealots will explain how publishers exploit scholars, profiting from the research, manuscripts, and peer review that they provide for free to the publishers, who then turn around and sell this research back to academic libraries in the form of journal subscriptions.

They will also tell you that Elsevier, the worst of the worst among publishers, actually created bogus journals to help promote a large pharmaceutical company's products. Imagine the horror. Because of this, we can never trust a subscription publisher again. Ever. Moreover, the advent of the Internet means that we really don't need publishers anymore anyway. We can self-publish our work or do it cooperatively. Libraries can be the new publishers. All we have to do is upload our research to the Internet and our research will be published, and the big publishers will wither up and die freeing up academic library budgets and creating a just and perfect system of scholarly publishing.

The story those promoting $O A$ tell is simple and convincing. Unfortunately, the story is incomplete, negligent, and full of bunk. I'm an academic crime fighter (Bohannon 2013b). I am here to set the record straight.

The logic behind the open-access movement is so obvious, simple, and convincing that no one could disagree with it, except that OA advocates don't tell the whole story. Open access will grant free access to research to everyone, including research-starved people in the Global South who have never read a scholarly article before. How could anyone oppose that? It will also allow everyone who has ever had the frustration of hitting a paywall when seeking a research article to access virtually everything for free, or so they claim.

\section{What the Open-Access Movement is Really About}

The open-access movement is really about anti-corporatism. OA advocates want to make collective everything and eliminate private business, except for small businesses owned by the disadvantaged. They don't like the idea of profit, even though many have a large portfolio of mutual funds in their retirement accounts that invest in for-profit companies. Salaries of 
academics in the United States have increased dramatically in the past two decades, especially among top professors and university administrators. OA advocates don't have a problem with this, and from their high-salaried comfortable positions they demand that for-profit, scholarly journal publishers not be involved in scholarly publishing and devise ways (such as green open-access) to defeat and eliminate them.

The open-access movement is a negative movement rather than a positive one. It is more a movement against something than it is a movement for something. Some will respond that the movement is not against anything; it is just for open access. But a close analysis of the discourse of the OA advocates reveals that the real goal of the open access movement is to kill off the for-profit publishers and make scholarly publishing a cooperative and socialistic enterprise. It's a negative movement.

This kind of movement, a movement to replace a free market with an artificial and highly regulated one, rarely succeeds. In fact, the gold open-access model actually incentivizes corruption, which speed the path to failure. The traditional publishing model, where publishers lived or died on subscriptions, encouraged quality and innovation. Publishers always had to keep their subscribers happy or they would cancel. Similarly, a movement that tries to force out an existing technology and replace it with a purportedly better one also never succeeds. Take the Semantic Web for example. It has many zealous advocates, and they have been promoting it for many years. Some refer to the Semantic Web as Web 3.0. However, despite intense promotion, it has never taken off. In fact, it is moribund. The advocates who promoted it spent a lot of time and blog space cheerleading for it, and they spent a lot of time trashing technologies and standards it was supposed to replace. In fact, that was what they did the most, badmouthing existing technologies and those who supported and used them. One example was a library standard called the MARC format. This standard was ridiculed so much it's a wonder it still even exists, yet is still being used successfully by libraries worldwide, and the semantic web is dying a slow death. Open access publishing is the "Semantic Web" of scholarly communication.

The open access movement and scholarly open-access publishing itself are about increasing managerialism (Grayson 2013). Wherever there is managerialism, there is an increased use of onerous management tactics, including mandatory record keeping, rationing of resources, difficult approval processes for things that ought to be freely allowed, and endless committee meetings, practices that generally lead to cronyism. The traditional publishing model had the advantage of there being no monetary transactions between scholarly authors and their publishers. Money, a source of corruption, was absent from the author-publisher relationship (except in the rare case of reasonable page charges levied on authors publishing with non-profit learned societies) in the traditional publishing model. Managerialism is the friend of those who want to restrict freedom and advancement. It is a tool for creating malevolent bureaucracies and academic cronyism. Managerialism is the logical and malevolent extension of office politics, and it will hurt scholarly communication. Many universities subsidize or pay completely for their faculty members' article processing charges when they submit to gold (author pays) open-access journals. The management of the funds used to pay these charges will further corrupt higher education. The powerful will have first priority for the money; the weak may remain unfunded. Popular ideas will receive funding; new and unpopular ideas, regardless of their merit, will remain unfunded. By adding a financial component to the front end of the scholarly publishing process, the open-access movement will ultimately corrupt scholarly publishing and hurt the communication and sharing of novel knowledge.

The open-access movement was born of political correctness, the dogma that unites and drives higher education. The open-access advocates have cleverly used and exploited political correctness in the academy to work towards achieving their goals and towards manipulating their colleagues into becoming open-access advocates. One of the ways they've achieved this is through the enactment of open-access mandates. The strategy involves making very simple arguments to faculty senates at various universities in favour of openaccess and then asking the faculties to establish the mandates. These mandates usually require that faculty use either the gold or green models of open-access publishing. OA advocates use specious arguments to lobby for mandates, focusing only on the supposed eco- 
nomic benefits of open access and ignoring the value additions provided by professional publishers. The arguments imply that publishers are not really needed; all researchers need to do is upload their work, an action that constitutes publishing, and that this act results in a product that is somehow similar to the products that professional publishers produce.

Nothing could be further from the truth, and the existence of the predatory publishers, the focus of my research, is evidence of this. It's likely that hundreds or even thousands of honest researchers have fallen prey to the predatory publishers, those open-access publishers that exploit the gold open-access model just for their own profit, pretending to be legitimate publishing operations but actually accepting any and all submissions just for the money. Institutional mandates feed into and help sustain predatory publishers.

Thus there are conscientious scholars, trying to follow the freedom-denying mandates imposed on them by their faculty representatives, who get tricked into submitting their good work to bogus journals.

There are numerous open-access advocates who promote scholarly open-access publishing without warning of the numerous scam publishers that operate all around the world. I find this promotion negligent. Anyone touting the benefits of open-access and encouraging its adoption ought also to warn of the numerous and increasing scams that exist in the scholarly publishing industry.

I believe many OA advocates ignore the known problems with scholarly open-access publishing because they don't want to frighten people away from it. This is the moral equivalent of selling someone a used car with the knowledge the engine block is cracked, without informing the buyer. Most descriptions and explanations of open-access publishing are idealistic and unrealistic. They tout the benefits but ignore the weaknesses. Many honest scholars have been seriously victimized by predatory publishers, and as a community we must help others, especially emerging researchers, avoid becoming victims. Pushing open access without warning of the possible scams is not helpful. In fact, it can be downright damaging to a scholar's career. For example, once a researcher unwittingly submits a paper to a predatory publisher, it is usually quickly published. Sometimes this fast publishing is the researcher's first clue that something is amiss. But by then it's too late, as once a paper is published in a predatory journal, no legitimate journal will be interested in publishing it. When this happens to early career researchers, it can have long-term negative effects on their careers.

I have observed that the advocates promoting open access do not want to hear any criticisms of the movement of the open-access publishing models, and they quickly attack anyone who questions the open-access or highlights its weaknesses. Open-access advocates are polemics; they have an "us versus them" mentality and see traditional publishers as the bad guys.

In April 2008, an article about predatory publishers appeared in the New York Times (Kolata 2013). The article described predatory publishers and predatory conferences. Immediately upon publication of the article, OA advocates sprang into action, questioning the article and its reporting. Numerous blog posts appeared, many attempting to cast doubt on the article. One perhaps slightly paranoid blog post was entitled "Did Commercial Journals Use the NYT to Smear Open Access?" (Bollier 2013). The fact is the predatory publishers do cast a negative light on all of scholarly open-access publishing. The gold open-access model in particular is flawed; there are only a few publishers that employ the model ethically, and many of these are cutting corners and lowering their standards because they don't have to fear losing subscribers.

On October 4, 2013, Science magazine published an article by John Bohannon (2013b) that related what the author learned from a sting operation he conducted on open-access publishers. The sting operation, which used my list of predatory publishers and the Directory of Open Access Journals as sources of journals, found that many journals accepted papers without even doing a peer review, and many did a peer review and accepted the unscientific article Bohannon baited them with anyway. Here again, the open-access advocates came out swinging, breaking into their "us versus them" stance, and attacking Bohannon, sometimes personally, for not including subscription journals in his study. Subscription journals were not part of his research question, however, but that didn't stop the many strident critics 
of Bohannon's work, who acted almost instinctively according to their Manichaean view of traditional and open-access publishing. He didn't need to gather data about traditional publishers; that wasn't what he was studying. If you are counting cars, you don't need to count airplanes as a control. Also, OA advocates often brag about the continually-increasing number of open-access outlets, predicting that traditional publishers will soon be eclipsed. So if the traditional publishers are nearly extinct, why bother to study them? The attack on Bohannon was carried out with a near religious fervour. OA advocates will do anything to protect the image of open-access. They don't care that the number of predatory publishers is growing at a near-relativistic speed; all they care about is that public perception of scholarly open access be kept positive.

Bohannon was interviewed by The Scholarly Kitchen contributor Phil Davis on November 12 , 2013. Summarizing the reaction of the open-access advocate community to his sting, Bohannon said, "I learned that I have been too naive and idealistic about scientists. I assumed that the results [of my study] would speak for themselves. There would be disagreements about how best to interpret them, and what to do about them, but it would be a civil discussion and then a concerted, rational, community effort to address the problems that the results reveal. But that is far from what happened. Instead, it was $100 \%$ political and many scientists that I respected turned out to be the most cynical political operators of all" (Bohannon 2013a). Interpreting the reaction to Bohannon's sting article publisher Kent Anderson, the president of the Society for Scholarly Publishing and former chief editor of the blog The Scholarly Kitchen commented, "... don't expect rational, calm, reasoned assessments from the likes of Eisen, Solomon, or others [open access advocates]. They've demonstrated they are ideologues that are quite willing to attack anyone who they view as falling outside their particular view of OA orthodoxy. How they are able to continue to deny what is actually happening is beyond me" (Anderson 2013).

When he served as the chief editor of The Scholarly Kitchen blog, Anderson was a frequent target of criticism from open-access zealots. I think this analysis from him sums up the attitude and actions of open access advocates quite well: "The attacks we've received when we've talked about OA have been surprisingly vitriolic and immature, even when we've said some things that were intended to point out issues the OA community might want to think about, in a helpful way. Some people really have a hair-trigger about anything short of complete OA cheerleading" (Anderson 2012).

One of the arguments that OA advocates use is that a lot of research is publically funded; therefore, the public deserves access to the research for free. This argument is true more in Europe more so than in the United States because collectivism is more institutionalized there. However, there are a lot of things that are publically funded that are not free, both in Europe and North America. Public transportation is one example. If OA advocates stuck to their principles, they would also be demanding that all publically owned buses and trains are free to all users. Their argument also completely ignores all the ways that publishers add value to information. This is done by selecting the best research for publication, managing the peer review process, managing ethics, maintaining servers, digital preservation, and the like. There are plenty of government-funded things that are not free, especially things to which the private sector adds value.

Building on this idea, I do find that the open-access movement is a Euro-dominant one, a neo-colonial attempt to cast scholarly communication policy according to the aspirations of a cliquish minority of European collectivists. Early funding for the open-access movement, specifically the Budapest Open Access Initiative, came from George Soros, known for his extreme left-wing views and the financing of their enactment as laws (Poynder 2002).

Another inconsistency in the open-access movement is that the zealots have been attacking scholarly journal publishers but generally ignoring scholarly monograph publishers, even though they operate using basically the same model, selling proprietary content to libraries. This is evidence that the open-access movement isn't really about making content openaccess; it's really about shutting down journal publishers. Were it a truly principled movement, it would apply its principals consistently. 
Some tenured open-access advocates are pressuring young scholars away from submitting their work to traditional journals, sacrificing them to the open-access movement. They are pressured to publish in OA journals despite their being able to publish in more esteemed traditional journals, which would better support their tenure cases. This pressuring helps the OA movement because it gets an increased amount of good research published in openaccess journals, but it hurts the individuals because it weakens their tenure dossiers. In the open-access movement, the needs of the many outweigh the needs of the few.

$\mathrm{OA}$ advocates are also pressuring scientists in developing countries to publish in OA journals, and this could hurt their careers. According to Contreras $(2012,60)$, "scientists in the developing world wish to publish in prestigious venues, with the greatest likely readership. Artificially forcing them to publish in oa journals of lesser impact could be resented and resisted, as it would be in the industrialized world". So, OA advocates also want to sacrifice the careers of developing-world scholars so that they can achieve their collectivist goals.

The gold OA model is merely shifting profits from one set of publishers to another, shifting the source of money from library subscriptions to those funding article processing charges, such as the provost's office, a researcher's grant itself, or even the library. That is to say, the open-access movement is dealing with the serials crisis by lowering or eliminating the subscription charges that libraries have to pay. But the money to support scholarly publishing has to come from somewhere. For those researchers lucky enough to have grants, they can pay the article processing charges out of grant money, but this means less money that they can spend on actual research. New funding sources are needed for university researchers who don't have grants. Thus, universities will have to initiate new funds to pay for the article processing charges their faculty incur when they publish in gold open-access journals. The proper distribution of these funds will require new committees and more university bureaucracy. Of course, journals charging APCs will charge more depending on the journal's status. That is to say, journals with higher impact factors will impose higher prices. The act of instituting financial transactions between scholarly authors and scholarly publishers is corrupting scholarly communication. This was one of the great benefits of the traditional scholarly publishing system - it had no monetary component in the relationship between publishers and their authors. Adding the monetary component has created the problem of predatory publishers and the problem of financing author fees.

Financing article processing charges will be most problematic in middle-income countries. Most non-predatory OA publishers grant fee waivers to scholars from lower-income countries (as long as they don't submit too many articles), but these waivers are generally not applied to many middle-income countries. Researchers in these countries are caught in a dilemma they aren't eligible for publisher-granted APC waivers, but their funding agencies lack the funds to subsidize the publication of their works, so they are left to fend for themselves when it comes to paying article processing charges.

And now we are seeing the emergence of mega gold-open-access publishers. I've documented that Hindawi's profit margin is higher than Elsevier's and achieves this by lowering standards (Beall 2013a). Hindawi has eliminated the position of editor-in-chief from most of the firm's over 550 journals. The company exploits Egypt's high unemployment rate by paying minimal salaries, employing college-educated staff desperate for jobs. It's an example of the scholarly publishing industry moving offshore. Moreover, because the journals lack editors, they have become desultory collections of loosely-related articles on a broad topic. The editorless journals lack coherence and vitality and function more like sterile repositories than scholarly publications. Open-access is killing the community function of scholarly journals, in which they served as fora for the exchange of both formal and informal communication among colleagues in a particular field or sub-field. Open access journals lack soul and are disconnected.

Open access advocates think they know better than everyone else and want to impose their policies on others. Thus, the open access movement has the serious side-effect of taking away other's freedom from them. We observe this tendency in institutional mandates. Harnad (2013) goes so far as to propose a table of mandate strength, with the most restric- 
tive pegged at level 12, with the designation "immediate deposit + performance evaluation (no waiver option)". This Orwellian system of mandates is documented in Table 1.

\begin{tabular}{|c|l|}
\hline \multicolumn{2}{|l|}{ Mandate strength } \\
\hline 12 & immediate deposit + performance evaluation (no waiver option) \\
\hline 9 & immediate deposit (no waiver option) \\
\hline 6 & six-month delay allowed (no waiver option) \\
\hline 3 & 12 -month delay allowed (no waiver option) \\
\hline 3 & rights-retention with waiver option \\
\hline 2 & deposit if/when publisher says it's OK \\
\hline 1 & no requirement: just request, recommendation or encouragement \\
\hline 0 & no policy in ROARMAP \\
\hline
\end{tabular}

Table 1: Open access mandates. Table copied from Harnad (2013) and reproduced under the terms of the Creative Commons BY-NC license.

A social movement that needs mandates to work is doomed to fail. A social movement that uses mandates is abusive and tantamount to academic slavery. Researchers need more freedom in their decisions not less. How can we expect and demand academic freedom from our universities when we impose oppressive mandates upon ourselves?

\section{Gold Open Access is Failing}

In 2006, James S. E. Opolot, Ph.D., a professor at Texas Southern University in Houston, published an article entitled "The Challenges of Environmental Crimes and Terrorism in Africa: Evidence from Eastern, Southern, and West African Countries" (Opolot 2006). The article was published in The International Journal of African Studies, one of the journals in the portfolio of the open-access (and predatory) publisher called Euro-Journals. One might assume that Euro-Journals would be based in Europe, but predatory publishers often disguise their true locations and use the names of Western countries to make themselves appear legitimate. Euro-Journals is based in Mauritius.

The open-access version of Professor Opolot's paper has disappeared from the Internet. Plagued by takedown requests due the high incidence of plagiarism among its articles, EuroJournals decided to switch the distribution model for some of its journals to the subscription model, and it removed all of their content from the open Internet. The publisher simply stopped publishing the balance of its journals, and it removed all of their content from the Internet as well. A blog post I wrote in March 2013 (Beall 2013b) showed that the publisher had 29 journals in its portfolio. Among these, 10 became toll-access journals, and nineteen disappeared from the Internet. Dr. Opolot's paper was published in one of the journals whose content was removed, apparently permanently, from the Internet. I expect this process to repeat itself many times over in the coming years with other open-access publishers.

One of the criteria I use when judging potential predatory publishers is whether they have a digital preservation strategy. Most gold open-access publishers have no idea what digital preservation is, even though digital preservation should be one of the top priorities of any scholarly publisher. Properly carried out, digital preservation ensures that content is safely stored and re-formatted as formats evolve. Legitimate scholarly publishers contract out their digital preservation to outfits like Portico and LOCKSS. Relying on one's web hosting service for digital preservation doesn't cut it. Virtually all the publishers and journals on my lists have devoted no resources to digital preservation nor do they have a business plan or strategy for it.

The open-access movement has been a blessing to anyone who has unscientific ideas and wants to get these ideas into print. Because the predatory publishers care very little about peer review and see it merely as a charade that must be performed, they don't really 
care when pseudo-science gets published in their journals, as long as they get paid for it. In my blog, I've given examples of pseudo-science being published as if it were true science. Here are three examples:

- The Theory of Metarelativity: Beyond Albert Einstein's Relativity (Jaoude 2013)

- Prevalence of Autism is Positively Associated with the Incidence of Type 1 Diabetes, but Negatively Associated with the Incidence of Type 2 Diabetes, Implication for the Etiology of the Autism Epidemic (Classen 2013)

- Combating Climate Change with Neutrinos (Wet 2013).

The last of these, "Combating Climate Change with Neutrinos", was summarily retracted (without any notice) by the publisher after I drew attention to it in a blog post (Beall 2013c). I saved a copy of the article's PDF and have made that document available on the blog post. There are many unscientific ideas that people can get published in scholarly journals thanks to predatory open-access publishing. Authors of these works find that their ideas fail peer review in legitimate journals, so they seek out predatory publishers that are more than happy to accommodate their publishing needs. Some of these ideas include issues relating to sealevel rise (or the lack of it), Sasquatch, anthropogenic global warming (or the lack of it), the aetiology of autism, and the nature of dark matter and dark energy.

Often promoted as one of the benefits of open-access is the fact that everyone, even the lay public, will have access to all the scientific literature. But in the context of pseudo-science being published bearing the imprimatur of science, this becomes a serious problem. People who are not experts in a given field generally lack both the ability to understand the most complex research in the field and the ability to distinguish between authentic and bogus research in the discipline. As more bogus research continues to be published open-access, it will be accessed more by the public, and many will accept it as valid research. This bogus research will poison discourse in many scientific fields and will create a public that is misinformed on many scientific issues.

Megajournals are becoming like digital repositories. These journals, many of them now editorless, are losing the cohesion, soul, and community-binding roles that scholarly journals once had. My website has its main list of publishers, but in early 2012 I was compelled to create a second list, a list of what I refer to as predatory standalone journals. These are predatory journals that cover the entire breadth of human knowledge, much broader than just science. Predatory publishers discovered the megajournal model by copying "successes" like PLOS ONE. As of late November 2013, I have 285 megajournals in my standalone journal list. They have titles like Journal of International Academic Research for Multidisciplinary [sic], International Journal of Sciences, and Current Discovery. The broad titles reflect the marketing strategy of accepting as many papers as possible, in order to maximize income. How many megajournals does the world need? Most of these journals exist only for the authors, those who need academic credit. Many of their articles will never be read, and many are plagiarized from earlier articles. The articles then become the source of future plagiarism. Collectively, they lower the quality of science and science communication. They clutter Google and Bing search results with academic rubbish.

The future of the Creative Commons Attribution License (CC BY) may be in doubt. Numerous companies are emerging that aggregate content from CC BY-licensed works, publish them in new formats, and sell them at a profit. Frequently, when scholars find out that their work has been published for profit without their knowledge, their first reaction is often anger, even though they freely assigned the free license to their work. They feel betrayed. The CCBY license has been promoted by European open-access advocates; the North Americans' view of open-access is more restrictive. Many here prefer to promote the CC BY NC (noncommercial) license. For many in North America, the concept of open-access itself means "ocular" open-access - that is, OA means that you can access content but can't do much else with it, other than read it. The Europeans are more collectivist and appropriative; for them scholarly publishing is another opportunity for taking. They do not respect the freedom of the press when the free press doesn't adopt their collectivist values. 
We mustn't forget the strengths of the traditional or subscription model of scholarly journal publishing. When space was an issue, journals could only publish the very best of the articles they received, and any lapse in quality over time led to subscription cancellations. The result was that the traditional journals presented the cream of the crop of current research. With open-access journals, the opposite is often true.

Indeed, when many libraries began to engage in journal cancellations in response to higher subscription prices (subscription prices increased mainly due to a great increase in the amount of scholarship being published), the subscription publishers came up with a solution that has greatly benefitted libraries: bundling and differential pricing. This innovation has greatly benefitted scholars by making a great amount of research affordable to academic libraries. On top of this, many publishers grant additional discounts to library consortia licensing journal subscriptions in bulk. According to Odlyzko $(2013,3)$ "the median of the number of serials received by ARL [Association of Research Libraries] members almost quadrupled during the period under investigation, going from 21,187 in the 1989-1990 academic year to 80,292 in the 2009-2010 one. Practically the entire increase took place during the last half a dozen years, without any big changes in funding patterns, and appears to be due primarily to 'Big Deals'". This finding shows the power of the market; when subscribers cut subscriptions, publishers take beneficial action for consumers.

OA journals don't have any space restrictions. They can publish as many articles per issue as they want, so the incentive for them is to publish more. We hear less about acceptance rates than we did in the past because of this.

Traditional journals didn't have the built-in conflict of interest that gold open-access journals have. For gold OA, the more papers a journal accepts, the more money it makes. Money is corrupting scholarly publishing. Scholars never should have allowed a system that requires monetary transactions between authors and publishers. Libraries took responsibility for this financial role in the past, and they performed it well. Now the realm of scholarly communication is being removed from libraries, and a crisis has settled in. Money flows from authors to publishers rather than from libraries to publishers. We've disintermediated libraries and now find that scholarly system isn't working very well.

\section{Conclusion}

The open-access movement isn't really about open access. Instead, it is about collectivizing production and denying the freedom of the press from those who prefer the subscription model of scholarly publishing. It is an anti-corporatist, oppressive and negative movement, one that uses young researchers and researchers from developing countries as pawns to artificially force the make-believe gold and green open-access models to work. The movement relies on unnatural mandates that take free choice away from individual researchers, mandates set and enforced by an onerous cadre of Soros-funded European autocrats.

The open-access movement is a failed social movement and a false messiah, but its promoters refuse to admit this. The emergence of numerous predatory publishers - a product of the open-access movement - has poisoned scholarly communication, fostering research misconduct and the publishing of pseudo-science, but OA advocates refuse to recognize the growing problem. By instituting a policy of exchanging funds between researchers and publishers, the movement has fostered corruption on a grand scale. Instead of arguing for openaccess, we must determine and settle on the best model for the distribution of scholarly research, and it's clear that neither green nor gold open-access is that model.

\section{References}

Anderson, Kent. 2012. Interview with The Scholarly Kitchen's Kent Anderson [Blog post]. Accessed on November 30, 2013. http://poynder.blogspot.com/2012/11/interview-with-scholarly-kitchenskent.html

Anderson, Kent. 2013. Post Open Access Sting: An Interview with John Bohannon [Blog post comment]. Accessed on November 30, 2013. http://scholarlykitchen.sspnet.org/2013/11/12/post-openaccess-sting-an-interview-with-john-bohannon/ 
Beall, Jeffrey. 2013a. Hindawi's Profit Margin is Higher than Elsevier's [Blog post]. Accessed on November 30, 2013. http://scholarlyoa.com/2013/04/04/hindawis-profits-are-larger-than-elseviers/

Beall, Jeffrey. 2013b. Hundreds of Articles Disappear as Publisher Changes Model from Open Access to Toll Access [Blog post]. Accessed on November 30, 2013. http://scholarlyoa.com/2013/03/19/disappearing-journals/

Beall, Jeffrey. 2013c. September 3. Weekend Update: Predatory Publishing News [Blog post]. Accessed on November 30, 2013. http://scholarlyoa.com/2013/09/03/weekend-update-predatorypublishing-news/

Bohannon, John. 2013a. Post Open Access Sting: An Interview with John Bohannon [Blog post]. Accessed on November 30, 2013. http://scholarlykitchen.sspnet.org/2013/11/12/post-open-accesssting-an-interview-with-john-bohannon/

Bohannon, John. 2013b. Who's Afraid of Peer Review? Science 342 (6154): 60-65.

Bollier, David. 2013. Did Commercial Journals Use the NYT to Smear Open Access? [Blog post]. Accessed on November 30, 2013. http://bollier.org/blog/did-commercial-journals-use-nyt-smear-openaccess- 0

Classen, John B. 2013. Prevalence of Autism is Positively Associated with the Incidence of Type 1 Diabetes, But Negatively Associated with the Incidence of Type 2 Diabetes, Implication for the Etiology of the Autism Epidemic. Open Access Scientific Reports 2: 679-681.

Contreras, Jorge. 2012. Open Access Scientific Publishing and the Developing World. St Antony's International Review 8 (1): 43-69.

Grayson, Kyle. 2013. Open Access Requirements Will Erode Academic Freedom by Catalysing Intensive Forms of Institutional Managerialism [Blog post]. Accessed on November 30, 2013. (http://blogs.Ise.ac.uk/politicsandpolicy/archives/33427

Harnad, Stevan. 2013. Worldwide Open Access: UK Leadership? UKSG Insights 26 (1): 14-21.

Jaoude, Abdo Abou. 2013. The Theory of Metarelativity: Beyond Albert Einstein's Relativity. Physics International 4 (2): 97-109.

Kolata, Gina. 2013. Scientific Articles Accepted (Personal Checks Too). New York Times, April 7.

Odlyzko, Andrew. 2013. Open Access, Library And Publisher Competition, And The Evolution Of General Commerce. Accessed on November 30, 2013. http://arxiv.org/abs/1302.1105

Poynder, Richard. 2002. George Soros Gives $\$ 3$ million to New Open Access Initiative. Information Today, February 18. Accessed on November 30, 2013. http://newsbreaks.infotoday.com/nbreader.asp?ArticlelD=17243

Wet, J. A. de. 2013. Combating Climate Change with Neutrinos. Environmental Sciences 1 (2): 79-82. http://scholarlyoa.files.wordpress.com/2013/09/combating-climate-change-with-neutrinos.pdf (accessed on November 30, 2013)

\section{About the Author}

\section{Jeffrey Beall}

is the Scholarly Initiatives Librarian at Auraria Library, University of Colorado Denver. An academic librarian for over 23 years, Beall's research and writing have appeared in Science, Nature, College and Research Libraries, The Charleston Advisor, The Journal of Academic Librarianship, and other journals. He is the author of the blog Scholarly Open Access (http://scholarlyoa.com/), a website that lists questionable journals and publishers and provides critical commentary on issues related to scholarly publishing. 